https://helda.helsinki.fi

On the origin of Solanum nigrum: can networks help?

\author{
Poczai, Peter
}

2011

Poczai , P \& Hyvönen , J 2011 , ' On the origin of Solanum nigrum: can networks help? ' , Molecular Biology Reports, vol. 38 , no. 2 , pp. 1171-1185 . https://doi.org/10.1007/s11033-010-0215-y

http://hdl.handle.net/10138/42434

https://doi.org/10.1007/s11033-010-0215-y

submittedVersion

Downloaded from Helda, University of Helsinki institutional repository.

This is an electronic reprint of the original article.

This reprint may differ from the original in pagination and typographic detail.

Please cite the original version. 


\title{
On the origin of Solanum nigrum: can networks help?
}

\author{
Péter Poczai · Jaakko Hyvönen
}

Received: 14 May 2010/Accepted: 11 June 2010/Published online: 24 June 2010

(C) Springer Science+Business Media B.V. 2010

\begin{abstract}
Black nightshades are a group of species best known for their 'poisonous' or noxious weedy reputation. It is not so well known that species of this group serve as emerging food source in many countries worldwide especially in the African continent. Despite the fact that the section has recently been studied extensively, taxonomy is still unsettled and debated because of inter- and intraspecific hybridization, phenotypic plasticity and polyploidization. In this study we analyze the genetic relationships among diploid, tetraploid and hexaploid species of sect. Solanum, which have possibly taken part in the formation of Solanum nigrum, utilizing multi-locus (SCoT, ISSR) markers combined with chloroplast $t r n L-F$ sequence data and morphological characters. We scored 51 morphological characters united with SCoT (171), ISSR (224) and trnL-F (1042), for simultaneous analysis of 49 terminals and 1488 characters. The topology of the tree is concordant with the results of the network analysis. In the phylogenetic networks, all the accessions of the diploid species shared a split with all of the polyploid species. This reflected a high portion of shared ISSR and SCoT bands between diploids and polyploids. In addition, a strong split divided the diploid species. The history of $S$. nigrum might be reticulate with hybrid speciation playing an important rule. Genetically differentiated diploids in few combinations have
\end{abstract}

Electronic supplementary material The online version of this article (doi:10.1007/s11033-010-0215-y) contains supplementary material, which is available to authorized users.

\footnotetext{
P. Poczai $(\bowtie) \cdot$ J. Hyvönen

Plant Biology, University of Helsinki, P.O. Box 65, 00014 Helsinki, Finland

e-mail: guanine@ex1.georgikon.hu

J. Hyvönen

e-mail: jaakko.hyvonen@helsinki.fi
}

created a series of genetically distinct polyploid populations. The insufficient isolation that permitted further recombination between ancient polyploids and diploids have resulted in high level of genotypic and phenotypic polymorphism. This high level of novel genomic variability obviously enabled species to succeed in their new environment.

Keywords Black nightshades - Solanum nigrum . Splits graphs · Phylogenetic networks .

Start codon targeted polymorphism (SCoT) . Inter-simple sequence repeats (ISSR)

\section{Introduction}

The genus Solanum L. comprises a wide range of economically important crop plants like potato (Solanum tuberosum L.), eggplant (Solanum melongena L.) and tomato (Solanum lycopersicum L.). Beside these major crops, the genus also contains many minor food plants like species of Solanum sect. Solanum, or black nightshades. They are known as poisonous weeds in many parts of the world, while in others they are used as valuable leafy vegetables. Because of this 'poisonous reputation', edible species of the group carry a negative disgrace, and thus are neglected or underutilized in Europe. Black nightshades serve as emerging food sources in Africa, but some varieties are cultivated elsewhere. However, no cultivars have yet been developed using traditional plant breeding techniques [1]. Large number of traditional landraces and varieties exist in regions where they are utilized as food and/or medical plants [2]. In addition to many local uses in Africa the species of sect. Solanum are potentially globally important for agriculture, human health, plant breeding and 
biotechnology. The leaves and berries are a potential source of coloring plant extracts, inks and dyes [3, 4], and they are rich in proteins, fibers, vitamins and amino acids [5-7]. The value of the group as a genetic resource for plant breeding is also very significant because $S$. nigrum L. is resistant to all known races of late blight-economically one of the most important diseases of solanaceous plantscaused by an oomycete Phytophthora infestans (Mont.) de Bary [8-11]. While resistance has been successfully transferred to the potato in some experiments [12-15]; the species has not proved to be a useful source for traditional breeding. However, the genes responsible for the resistance (R) might be cloned and introduced to the potato [16] offering a promising new gene pool of possible $\mathrm{R}$ genes $[17,18]$.

Section Solanum, also known as the $S$. nigrum complex, is composed of 50 species [19] and it is one of the most variable groups of the genus [20]. Polyploidy and hybridization is often reported as an important source of diversity [21], while members of the group are phenotypically diverse. Natural inter- and intraspecific hybrids have been described [22-26], as well as individuals with higher level of ploidy among diploid and hexaploid taxa [24, 27-29]. Since the description of $S$. nigrum by Linnaeus [30] more than 30 names have been published referring to the same species. The great number of junior synonyms has resulted in large number of conflicting and confusing species definitions [31-33]. Despite the fact that the group has recently been studied extensively [34-41], its taxonomy is still unsettled and debated [31].

The section is placed to the Morelloid clade in the 13 clade scheme of Bohs [42]—which is being used for example to arrange the taxa for the PBI Solanum project based on $n d h \mathrm{~F}$ sequence data. According to Weese and Bohs [43] and Poczai et al. [44] the Morelloid clade is closely related to the representatives of the Dulcamaroid clade (e.g. Solanum dulcamara L.). While the infrageneric relationships have been studied in detail [45-51], much less is known about the relationships of the species. To address important question about biogeography, genetic diversity and relationships, markers covering the whole genome (e.g. AFLP, RAPD, ISSR) are often used [52, 53]. In the case of the $S$. nigrum complex molecular markers like RAPDs have been used by Stracke et al. [54] to study genetic variation among GenBank accessions of Solanum americanum Mill., S. nigrum and Solanum melanocerasum All. The same technique was successfully used by Poczai et al. [44] to assess genetic diversity among common species of the section found in Europe and later to clarify the origin of rarely cultivated edible varieties [55]. AFLP and SSR markers have also been used [56-58] to characterize genetic diversity among the germplasm accessions of the Gatersleben GenBank as well as to classify taxonomically unknown material. These studies simultaneously uncovered significant differences among the accessions of $S$. americanum. AFLPs were used to study different genotypes of black nightshades alongside with interbreeding studies to reveal interspecific relationships between species occurring in South Africa [59], Uganda [60, 61] and other parts of Africa [62, 63]. DNA sequence analyses have not been so widely used in studies of this group, but Poczai et al. [64] used rDNA ITS data, along with ITS2 RNA transcript secondary structure modeling, to reveal the origin of an ambiguous historical Solanum scabrum Mill. herbarium specimen from the eighteenth century collected by Paulus Kitaibel.

The cited studies clearly reveal that even with the use of molecular methods the species of the group cannot be identified easily. In addition, it is quite obvious that new phylogenetic methods (e.g. phylogenetic network modeling) with the aim to detect non-tree like evolutionary histories will be needed for successful phylogenetic studies of this group. Conventional phylogenetic methods assume that evolutionary history can be represented by means of bifurcating trees [65]. However, it is likely that large number of angiosperm species have arisen through hybridization [66], and thus their history would be better represented as a network [67]. Many new algorithms have been developed to model and visualize reticulating events [68-70].

In this study we aimed to analyze genetic relationships among diploid, tetraploid and hexaploid species of sect. Solanum, which have possibly taken part in the formation of $S$. nigrum, utilizing multi-locus (SCoT, ISSR) markers along with chloroplast $t r n L-F$ sequence data and morphological characters. We aimed to investigate: (1) whether relationships of these species will be better represented as a reticulate rather than tree-like, and (2) by using a network method we aimed to study relationships between these species at genome level.

\section{Materials and methods}

\section{Plant material and DNA extraction}

A total of 48 accessions of $S$. nigrum related, diploid (S. americanum, Solanum physalifolium, Solanum chenopodioides), tetraploid (Solanum retroflexum, Solanum villosum) and hexaploid (Solanum opacum, S. scabrum) taxa were used in this study. Although, almost 50 taxa belong to sect. Solanum, we have chosen to analyze the most relevant species which have possibly taken part in the formation of $S$. nigrum as implicated in previous studies [44, 55, 58, 62]. Identification of the species followed Edmonds and Chweya [2]. We recognize S. americanum 
and $S$. nodiflorum here as separate taxa after Manoko et al. [62]. S. americanum is an aggregate species but detailed analysis of this complex is outside the scope of the present study. One $S$. dulcamara entry was used as an outgroup following the results by Manoko et al. [62, 63]. Details about the plant material used in this study are listed in Table 1.

DNA was extracted according to the following protocol: $50 \mathrm{mg}$ of fresh young leaves were suspended in $1 \mathrm{ml}$ of Solution I $(50 \mathrm{mM}$ Tris- $\mathrm{HCl}, 50 \mathrm{mM}$ EDTA, $500 \mathrm{mM}$ $\mathrm{NaCl}, 15 \%$ sucrose, $\mathrm{pH} 8.0$ ). The tissues were crushed and homogenized, for complete cell lyses and disruption, using a mixer mill (Retsch MM 301, Germany) and sterile steal beads for $10 \mathrm{~min}, 30 \mathrm{~s}^{-1}$. The lysated samples were centrifuged at room temperature for $5 \mathrm{~min}$ at $8,000 \mathrm{rpm}$. The supernatant was discarded and the remaining pellet was dissolved in $300 \mu \mathrm{l}$ of $20 \mathrm{~T}-10 \mathrm{E}$ buffer $(20 \mathrm{mM}$ Tris- $\mathrm{HCl}$, $10 \mathrm{mM}$ EDTA, pH 8.0) and $20 \mu \mathrm{l} 10 \%$ SDS solution was added. The samples were incubated for $15 \mathrm{~min}$ at $70^{\circ} \mathrm{C}$ and gently shaken a few times. After the incubation $150 \mu \mathrm{l}$ of 7.5 M sodium acetate was added, and the samples were placed on ice for $1 \mathrm{~h}$ and centrifuged for $10 \mathrm{~min}$, $15,000 \mathrm{rpm}$ at $4^{\circ} \mathrm{C}$. The flow through (approx. $400 \mu \mathrm{l}$ ) was transferred to new Eppendorf tubes and $500 \mu \mathrm{l}$ of ice-cold isopropanol was added to precipitate DNA. The samples were kept at $4^{\circ} \mathrm{C}$ for $30 \mathrm{~min}$ and then centrifuged for $5 \mathrm{~min}, 8,000 \mathrm{rpm}$ at $4^{\circ} \mathrm{C}$. The flow through was removed; DNA was recovered as a pellet and dissolved in $500 \mu \mathrm{l}$ of TE buffer (10 mM Tris-HCl, 1 mM EDTA, pH 8.0) equal volume of CIA (chloroform:isoamyl-alcohol, 24:1) was added and the samples were shaken for $15 \mathrm{~min}$ at $300 \mathrm{rpm}$ and then centrifuged for $15 \mathrm{~min}, 15,000 \mathrm{rpm}$ at room temperature. The upper phase was transferred to a new Eppendorf. $1 \mathrm{ml}$ of $99.9 \%$ ethanol and $40 \mu \mathrm{l}$ of ammonium acetate was added to the samples and then centrifuged for $10 \mathrm{~min}, 15,000 \mathrm{rpm}$ at $4^{\circ} \mathrm{C}$. The supernatant was removed and the pellet was washed again with $500 \mu \mathrm{l}$ of $70 \%$ ethanol and centrifuged for $5 \mathrm{~min}, 15,000 \mathrm{rpm}$ at $4^{\circ} \mathrm{C}$. The tubes were placed upside down and air dried. Finally the DNA was dissolved in $200 \mu \mathrm{l} \mathrm{TBE}$ (Tris-Borate-EDTA pH 8.0) and stored at $-20^{\circ} \mathrm{C}$. The DNA concentration was measured with fluorodensitometric analysis (GeneTools, Syngene UK) after electrophoresis and ethidium-bromide post-staining using the GeneRuler $1 \mathrm{~kb}$ Ladder (Fermentas, Lithuania) separated on $1 \%$ agarose gel.

\section{Morphological analysis}

We compiled a matrix of 51 morphological characters measured and coded as multistate characters. Forty of the characters were qualitative and 11 were quantitative traits. Characters were taken and measured from approximately the same position of each plant. Leaf characters were taken from the fourth true leaf of each individual while floral characters from the uppermost inflorescence. Four individuals from each accession were measured. The mean values of these plants and accessions were used as representatives of each taxon. Data collected here was compared with previous descriptions and studies on section Solanum $[2,20,40]$. The list and the matrix of the morphological characters are presented in Online Resources 1 and 2.

\section{ISSR and SCoT amplification}

We chose arbitrary amplified DNA (AAD) markers for our study to generate fragments that are randomly generated by inter-simple sequence repeats (ISSR) or start codon targeted (SCOT) over the whole genome [71]. Recent studies [72-75] have shown that AAD markers can solve phylogenetic relationships of closely related, recently radiated taxa at low taxonomic levels [76-78]. However, one of the arguments against the use of AADs is that they are homoplastic-co-migration of non-identical bands-causing noise instead of phylogenetic signal in the datasets [79, 80]. The species of the sect. Solanum are assumed to be very closely related and homoplasy becomes a greater problem where distantly related species are involved; it is less likely to cause problems for studies of very closely related species $[72,81]$. This assumption certainly applies to Solanum where the utility of multi-locus methods in phylogenetic reconstruction have repeatedly been used at species level [82-86].

Sixteen ISSR and 12 SCoT primers were selected for further study, after a screening and optimization process with 50 primers for each method. Degenerate nucleotide anchoring was used for some ISSR primers. The selected primers yielded stabile and reproducible banding patterns. Amplification reactions were performed in $10 \mu \mathrm{l}$ volumes in 384-well plates containing: $5 \mu \mathrm{l} \mathrm{NFW} \mathrm{(Nuclease} \mathrm{Free}$ Water, Promega), approx. $20 \mathrm{ng}$ template DNA, $0.5 \mu \mathrm{M}$ of each primer, $0.2 \mathrm{mM}$ dNTP (Fermentas, Lithuania), $1 \mu 1$ $10 \times$ PCR buffer $\left(1 \mathrm{mM}\right.$ Tris- $\mathrm{HCl}, \mathrm{pH} 8.8$ at $25^{\circ} \mathrm{C}, 1.5 \mathrm{mM}$ $\mathrm{MgCl}_{2}, 50 \mathrm{mM} \mathrm{KCl}$ and $0.1 \%$ Triton $\left.\mathrm{X}-100\right)$ and $0.5 \mathrm{U}$ of DyNazyme II (Finnzymes, Finland) polymerase. All reactions were done in a MasterCycler ep384 (Eppendorf, Germany) with the following conditions: $2 \mathrm{~min}$ at $94^{\circ} \mathrm{C}$ for initial denaturation, 35 cycles of $30 \mathrm{~s}$ denaturation at $94^{\circ} \mathrm{C}$, $1 \mathrm{~min}$ annealing at $50^{\circ} \mathrm{C}$, and $2 \mathrm{~min}$ extension at $72^{\circ} \mathrm{C}$, followed by a final extension for $5 \mathrm{~min}$ at $72^{\circ} \mathrm{C}$. Amplification products were separated on $1.5 \%$ agarose gels (Promega, USA) in $0.5 \times$ TBE buffer $(300 \mathrm{~V}, 1.5 \mathrm{~h})$ and post-stained with ethidium-bromide. The gels were documented using the GeneGenius Bio Imaging System (Syngene, UK). Although, ISSRs and SCoTs were found to be reproducible in our experiments-due to higher annealing temperature and longer anchored primers-replicate 
Table 1 Taxonomic information about all Solanum plant species used in the study

\begin{tabular}{|c|c|c|c|c|c|c|}
\hline No. & Accession number & Accession code & Taxon & Received & Origin & Voucher $^{\mathrm{a}}$ \\
\hline \multicolumn{7}{|c|}{ Ingroup } \\
\hline 1 & HUGEO09022 & Ame01 & S. americanum Mill. & $\mathrm{G}$ & Australia & UPG0001 \\
\hline 2 & HUGEO09020 & Ame02 & S. americanum Mill. & G & Hungary & UPG0002 \\
\hline 3 & HUGEO09023 & Ame03 & S. americanum Mill. & G & Australia & UPG0003 \\
\hline 4 & 904750023 & Ame04 & S. americanum Mill. & $\mathrm{N}$ & USA & UPG0004 \\
\hline 5 & HUGEO09024 & Ame05 & S. americanum Mill. & G & Australia & UPG0005 \\
\hline 6 & HUGEO09021 & Ame06 & S. americanum Mill. & G & Hungary & UPG0006 \\
\hline 7 & 884750042 & Che01 & S. chenopodioides Lam. & $\mathrm{N}$ & Swizerland & UPG0007 \\
\hline 8 & HUGEO09025 & Che02 & S. chenopodioides Lam. & G & France & UPG0008 \\
\hline 9 & UHBG211-1470 & Che03 & S. chenopodioides Lam. & $\mathrm{H}$ & Germany & UPG0009 \\
\hline 10 & HUGEO09005 & Che04 & S. chenopodioides Lam. & G & Hungary & UPG0010 \\
\hline 11 & HUGEO09026 & Che05 & S. chenopodioides Lam. & G & Romania & UPG0011 \\
\hline 12 & HUGEO09027 & Che06 & S. chenopodioides Lam. & G & Hungary & UPG0012 \\
\hline 13 & HUGEO06004 & Nig01 & S. nigrum $^{1} \mathrm{~L}$. & $\mathrm{G}$ & Hungary & UPG0013 \\
\hline 14 & HUGEO06005 & Nig02 & S. nigrum $^{2} \mathrm{~L}$. & G & Hungary & UPG0014 \\
\hline 15 & HUGEO06006 & Nig03 & S. nigrum $^{2} \mathrm{~L}$. & G & Hungary & UPG0015 \\
\hline 16 & HUGEO09028 & Nig04 & S. nigrum $^{2} \mathrm{~L}$. & G & Croatia & UPG0016 \\
\hline 17 & HUGEO09029 & Nig05 & S. nigrum $^{2} \mathrm{~L}$. & G & Romania & UPG0017 \\
\hline 18 & HUGEO09030 & Nig06 & S. nigrum $^{1} \mathrm{~L}$. & G & Italy & UPG0018 \\
\hline 19 & 884750223 & Opa01 & S. opacum A.Braun\&Bouché & $\mathrm{N}$ & Unknown & UPG0019 \\
\hline 20 & HUGEO09015 & $\mathrm{Opa02}$ & S. opacum A.Braun\&Bouché & $\mathrm{G}$ & Australia & UPG0020 \\
\hline 21 & HUGEO09016 & Opa03 & S. opacum A.Braun\&Bouché & G & Australia & UPG0021 \\
\hline 22 & HUGEO09017 & Opa04 & S. opacum A.Braun\&Bouché & G & Australia & UPG0022 \\
\hline 23 & HUGEO09018 & Opa05 & S. opacum A.Braun\&Bouché & $\mathrm{G}$ & Australia & UPG0023 \\
\hline 24 & HUGEO09019 & Opa06 & S. opacum A.Braun\&Bouché & G & Australia & UPG0024 \\
\hline 25 & 894750076 & Phy01 & S. physalifolium ${ }^{3}$ Rusby & $\mathrm{N}$ & Germany & UPG0025 \\
\hline 26 & HUGEO09010 & Phy02 & S. physalifolium ${ }^{3}$ Rusby & G & Hungary & UPG0026 \\
\hline 27 & HUGEO09011 & Phy03 & S. physalifolium ${ }^{3}$ Rusby & G & Hungary & UPG0027 \\
\hline 28 & HUGEO09012 & Phy04 & S. physalifolium ${ }^{3}$ Rusby & G & Romania & UPG0028 \\
\hline 29 & HUGEO09013 & Phy05 & S. physalifolium ${ }^{3}$ Rusby & $\mathrm{G}$ & Romania & UPG0029 \\
\hline 30 & HUGEO09014 & Phy06 & S. physalifolium ${ }^{3}$ Rusby & G & Slovakia & UPG0030 \\
\hline 31 & PI63475502SD & Ret01 & S. retroflexum Dunal & $\mathrm{U}$ & USA & UPG0031 \\
\hline 32 & HUGEO09006 & Ret02 & S. retroflexum Dunal & G & USA & UPG0032 \\
\hline 33 & HUGEO09007 & Ret03 & S. retroflexum Dunal & G & Australia & UPG0033 \\
\hline 34 & HUGEO09009 & Ret04 & S. retroflexum Dunal & G & South Africa & UPG0034 \\
\hline 35 & 904750228 & Ret05 & S. retroflexum Dunal & $\mathrm{N}$ & Australia & UPG0035 \\
\hline 36 & HUGEO09008 & Ret06 & S. retroflexum Dunal & G & Australia & UPG0036 \\
\hline 37 & 824750011 & Sca01 & S. scabrum Mill. & $\mathrm{N}$ & Unkonwn & UPG0037 \\
\hline 38 & Grif1419801SD & Sca02 & S. scabrum Mill. & $\mathrm{U}$ & USA & UPG0038 \\
\hline 39 & HUGEO09004 & Sca03 & S. scabrum Mill. & G & Uganda & UPG0039 \\
\hline 40 & UHBG211-1465 & Sca04 & S. scabrum Mill. & $\mathrm{H}$ & Germany & UPG0040 \\
\hline 41 & HUGEO09002 & Sca05 & S. scabrum Mill. & G & South Africa & UPG0041 \\
\hline 42 & HUGEO09003 & Sca06 & S. scabrum Mill. & G & South Africa & UPG0042 \\
\hline 43 & HUGEO09031 & Vil01 & S. villosum ${ }^{4} \mathrm{~L}$. & G & Hungary & UPG0043 \\
\hline 44 & HUGEO09032 & Vil02 & S. villosum ${ }^{4} \mathrm{~L}$. & $\mathrm{G}$ & Romania & UPG0044 \\
\hline 45 & HUGEO09033 & Vil03 & S. villosum ${ }^{5} \mathrm{~L}$. & G & Hungary & UPG0045 \\
\hline 46 & 804750186 & Vil04 & S. villosum ${ }^{5} \mathrm{~L}$. & $\mathrm{N}$ & Unknown & UPG0046 \\
\hline 47 & HUGEO09034 & Vil05 & S. villosum ${ }^{4} \mathrm{~L}$. & G & Unknown & UPG0047 \\
\hline
\end{tabular}


Table 1 continued

\begin{tabular}{llllllr}
\hline No. & Accession number & Accession code & Taxon & Received & Origin $^{\text {Voucher }}$ \\
\hline 48 & HUGEO09035 & Vil06 & S. villosum ${ }^{4}$ L. & G & Unknown \\
$\begin{array}{l}\text { Outgroup } \\
49\end{array}$ & S001/2009 & Dul01 & S. dulcamara L. & V & Hungary & UPG0049 \\
\hline
\end{tabular}

${ }^{a}$ University of Pannonia, Georgikon Faculty Voucher System of the Department of Plant Science and Biotechnology

$G$ Georgikon Botanical Garden, University of Pannonia, Keszthely, Hungary; $H$ Botanical Garden of the University of Hohenheim, Stuttgart, Germany; $N$ Botanical and Experimental Garden of the Radboud University Nijmegen, The Netherlands; $U$ National Plant Germplasm System (NPGS), Plant Genetic Resources Conservation Unit, Griffin, GA, USA; V Botanical Gardens, Institute of Ecology and Botany, Hungarian Academy of Sciences, Vácrátót, Hungary

${ }^{1}$ subsp. shultesii; ${ }^{2}$ subsp. nigrum; ${ }^{3}$ var. nitidibaccatum; ${ }^{4}$ subsp. villosum; ${ }^{5}$ subsp. miniatum

experiments were performed, containing one negative and positive control, to check the reliability of the primers and the patterns produced.

Chloroplast $\operatorname{trn} L-F$ amplification, cloning and sequencing

PCR amplifications and treatment of the $t r n L-F$ chloroplast region followed the procedures described by Bohs and Olmstead [49]. Primers described by Taberlet et al. [87] were used in all reactions. For the cloning procedure, the amplified products were excised from the agarose gel and cleaned using the SpinPrep Gel DNA Kit (Novagen, Germany). The fragments were cloned using the pGem-T Vector System (Promega, USA) and DH5 $\alpha$ competent Escherichia coli strains. The procedure was carried out according to the manufacturer's protocols. The desired white colonies holding the insertion were selected and screened applying a colony-PCR. For the procedure white colonies were picked up and used directly as DNA template in the amplification process. For the amplification the primers SP6 (5'-ATTTA GGTGACACTATAG- $3^{\prime}$ ) and T7 (5'-TAATACGACTCAC TATAGGG- $3^{\prime}$ ) were used, designed to anneal in the lac $Z$ gene upstream and downstream from the T7 RNA polymerase transcription initiation site, respectively. The cycling parameters were: $94^{\circ} \mathrm{C}$ for $2 \mathrm{~min}$, followed by 35 cycles of $94^{\circ} \mathrm{C}, 40 \mathrm{~s}$ denaturation, $48^{\circ} \mathrm{C} 30 \mathrm{~s}$ annealing, $72^{\circ} \mathrm{C} 1 \mathrm{~min}$ extension, and one additional extension cycle at $72^{\circ} \mathrm{C}$ for $5 \mathrm{~min}$. Plasmids were extracted from the selected white colonies using the EZ-10 Spin Column Plasmid DNA Kit (Bio Basic Inc., Canada). Sequencing was done using the T7 and pUC/M13 (5'-CAGGAAACAGCTATGAC-3') reverse primers, in an $\mathrm{ABI} 3100$ for three selected colonies. All sequences are deposited at NCBI GenBank. Accession numbers and further details are given in Table 2.

Band scoring and data analysis

The evaluation of the binding patterns was carried out with the program GeneTools (Syngene, UK). Kingston and
Table 2 Accession numbers for chloroplast trnL-F sequences used in this study

\begin{tabular}{ll}
\hline Species name & Sequence accession numbers \\
\hline S. americanum & GU169332 \\
S. chenopodioides & GU169331 \\
S. nigrum & AY349002 \\
S. opacum & DQ855059 \\
S. physalifolium & EF068253 \\
S. retroflexum & AY348999 \\
S. scabrum & GU169330 \\
S. villosum & DQ180459 \\
Outgroup & \\
S. dulcamara & AY266231
\end{tabular}

Note: The sequences will be published by NCBI GenBank after acceptance

New seqence provided by this study are in bold

Rosel [88] described a conservative scoring protocol that was used also here to prevent problems associated with multi-locus methods, e.g.: uneven amplification among samples and poor amplification of larger fragments for degraded DNA samples. Only well-resolved, distinct bands were scored. Amplicons found in replicate reactions were considered reliable. The amplified fragments were coded as absent/present $(0 / 1)$. It was presumed that fragments with equal length had been amplified from homologous loci and represents a single, dominant locus with two possible alleles. To measure the information content detected with each primer the Polymorphic Information Content (PIC) value was calculated, according to Botstein et al. [89]. The heterozigosity $(H)$ value was also calculated according to Liu [90]. For all calculation the test version of the online program PICcalc was used [91]. As PIC and $H$ are both influenced by the number and frequency of alleles, the maximum number for a dominant marker is 0.5 , since two alleles per locus are assumed in the analysis [92-94]. For all data about the primers and calculated values see Online Resource 3. 
Phylogenetic network analysis

The network analysis was carried out to study whether reticulating or tree-like evolutionary graphs would be better representations of the phylogeny for the selected set of terminals. A NeighborNet (NNet) analysis was carried out with SplitsTree v. 4.6 [95]. We conducted a NNet analysis with the separate ISSR and SCoT dataset and also with the joined dataset. All calculations were based on uncorrected $p$-distances where splits (bipartitions) were represented as parallel edges. The resulting splits graphs were filtered with a 95\% threshold level to include only the splits with high support values.

We also constructed a supernetwork from the collection of trees resulting from the parsimony analysis of the combined ISSR and SCoT dataset using the supernetwork construction function of SplitsTree. The congruence or incongruence of the resulting trees and graphs was used to infer recombination, which was tested using the Phi-test implemented in SplitsTree. This test uses the pairwise homoplasy index, $\Phi$ statistic, to detect refined incompatibility indicating recombination [96]. This was done with the filtered taxon set including only the analyzed diploid species ( $S$. americanum, S. chenopodioides, S. physalifoli$u m$ ) to detect splits resulting from false negatives.

\section{Simultaneous analyses}

ClustalX version 1.83.1 [97] with default settings was used to align $t r n L-F$ sequences. Last 24 nucleotides by $3^{\prime}$ prime for $S$. nigrum, S. retroflexum and S. villosum, and 12 nucleotides for $S$. chenopodioides and S. scabrum were removed as unalignable with other species. Conventional phylogenetic analyses were performed using parsimony as an optimality criterion. These were performed with NONA [98] in conjunction with a Winclada shell [99]. Fifty-one morphological characters were united with SCoT (171), ISSR (224) and trnL-F (1042 characters, the latter converted into numeric form using winclada) data to a concatenated matrix of 49 terminals and 1,488 characters. Three hundred and eighty-three of these were parsimony informative (34 morphology, 142 SCoT, 200 ISSR and 6 $\operatorname{trn} L-F)$. While there were several accessions for each species for SCoT and ISSR, both morphology and trnL-F were scored as identical for all terminals of the same species (an assumption that can be challenged). We analyzed also a reduced matrix so that each species was represented by the least divergent (based on the results of larger matrix) terminal in order to see if the same topology for species level relationships was obtained also in this case. Analyses of larger matrix were performed with the following settings: hold 90,000 (holding defined number of trees), 30,000 replications (search performed with multiple tree-bisection-reconnection algorithm mult*max*), hold/3 (keeping three starting trees for each replication). Analysis was further enlarged by holding up to 180,000 trees (hold 180,000) and keeping 60 starting trees for each replication (hold/60). Also a small, restricted analysis on the large matrix was performed with the settings hold 100, 50 replications (mult*max*), hold/1. A smaller matrix with nine terminals (based on the analyses of the larger matrix the terminal in the basal position within each species clade) and 383 informative characters was analyzed with TNT version 1.1 [100]. Because of its small size we were able to use a command (ienum) that ensures finding the shortest tree for this matrix. The assembled data matrix is given in Online Resource 4.

\section{Results}

Network analysis

The snapshot of the combined ISSR and SCoT dataset (Fig. 1) obtained by NNet analysis provided a general representation of the genetic relationships of the terminals. The planar property of the NNet algorithm-which is an explicit extension of Neighbor-Joining [101]-represents conflicting signals in the dataset. In addition, NNet split graphs highlight the predominant signals in the data and the extent to which these signals may or may not be tree-like [70]. Reticulate evolutionary history is displayed as the occurrence of incompatible splits or parallel edges in the resulting split graphs. It is often reported that taxa formed by reticulate evolutionary patterns or hybridizations are linked by splits to their potential parents [102]. However, the constructed graphs by NNet algorithm display only the contradictory signals which are visualized in a planar graph. These graphs can not be considered explicitly as a model of reticulate evolution although it was recently shown that there is a strong correlation between split graphs and reticulate history [103-106].

In this study, all the accessions of the diploid species shared a split with all of the polyploid species. This split reflects a high portion of shared ISSR and SCoT bands between diploids and polyploids. Another major split divides $S$. nigrum $(6 \times)$ and $S$. villosum $(4 \times)$ together with S. scabrum $(6 \times)$. In addition, a strong split also occursdividing the diploid species-and linking them together with the polyploids in a different context. The accessions of $S$. americanum $(2 \times)$ share a weak split with $S$. nigrum, S. villosum and $S$. scabrum (Fig. 1) and they form a circular 'splits rose' (Fig. 2). A clear parallel edge links the terminals of $S$. chenopodioides $(2 \times)$ and $S$. physalifolium $(2 \times)$ with $S$. retroflexum $(4 \times)$ and $S$. opacum $(6 \times)$. While the constructed supernetwork from the eight equally 


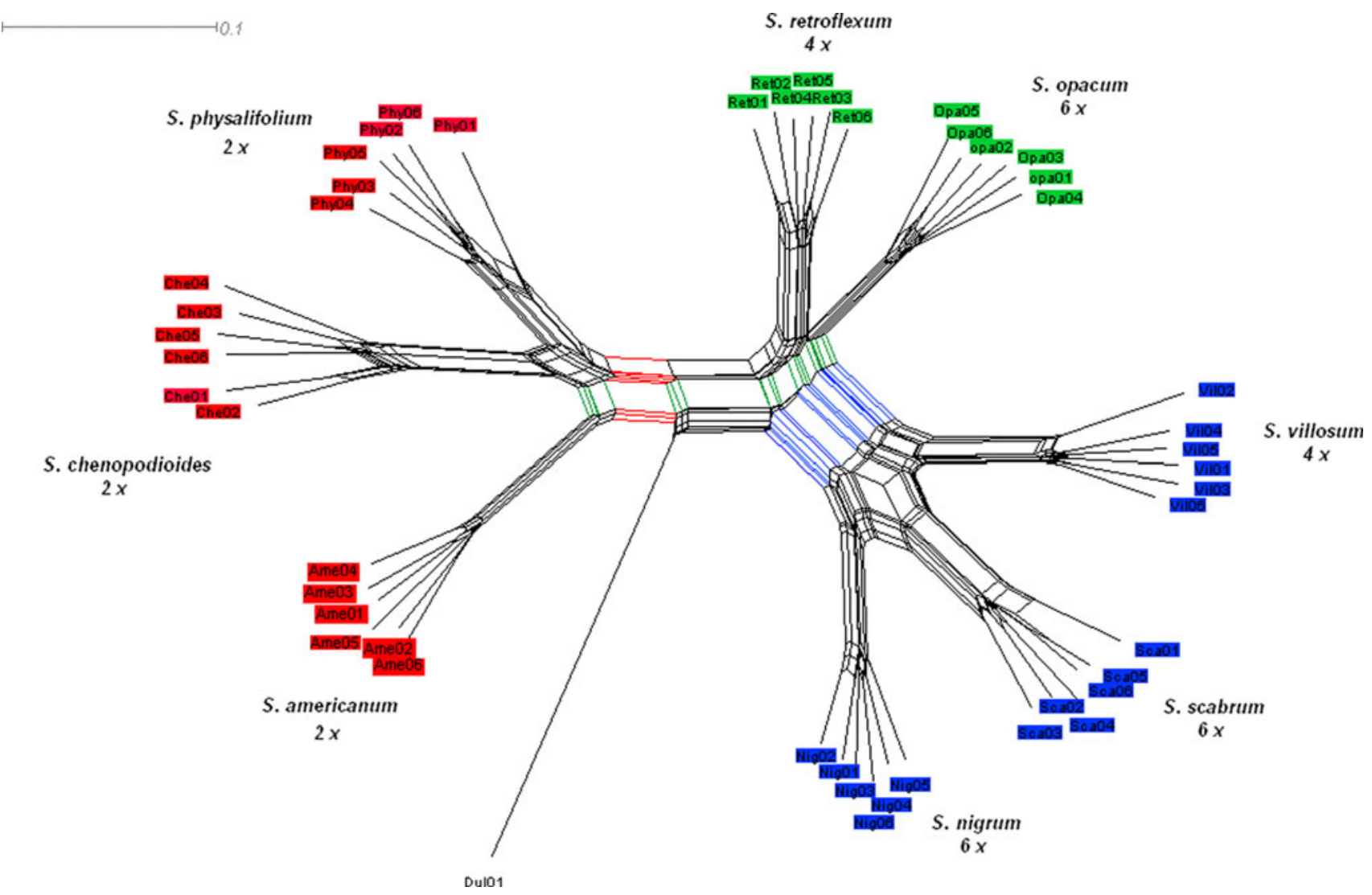

Fig. 1 NeighborNet planar graphs of the combined ISSR and SCoT binary data matrix based on the uncorrected $p$-distance for sect. Solanum and $S$. dulcamara as outgroup. NNet for 395 polymorphic loci (ISSR and SCoT) and 49 accessions, based on uncorrected $p$ distances, filtered with 0.95 threshold level. Abbreviations are listed in Table 1. Relevant splits separating the diploids and polyploids are

parsimonious trees obtained for the joined ISSR\&SCoT data was almost tree like (Fig. 3).

We also made a more specific analysis by excluding the terminals of other species to study the evolutionary history of $S$. nigrum (Fig. 2). This was done in order to test hypothesis based on previous studies, e.g. [24, 107, 108]. The separate Phi test of the filtered diploid taxon set with the joined ISSR\&SCoT data matrix found 222 informative sites, but did not find statistically significant evidence for recombination $(P=0.5081)$.

Simultaneous analyses

All performed analyses of the combined large matrix, even the one with only 100 replicates, obtained the same set of eight equally parsimonious trees (EPTs). The relationships of the terminals at species level on all of these trees were the same and can be presented in parenthetical notation as: (S. dulcamara ( $S$. americanum ( $S$. chenopodioides S. physalifolium)) ((S. retroflexum S. opacum) (S. nigrum (S. scabrum $S$. villosum)))). The only difference obtained highlighted. Red color splits separating S. americanum, S. chenopodioides and $S$. physalifolium var. nitidibaccatum; blue splits separating S. nigrum; S. scabrum and S. villosum; green splits separating $S$. retroflexum and $S$. opacum. Further details are discussed in the text

with the analysis of smaller reduced matrix was in the position of $S$. opacum - it was in the basal position in the clade including $S$. nigrum, $S$. scabrum and $S$. villosum, not as a sister of $S$. retroflexum.

\section{Discussion}

Our results could be challenged by larger analyses, both in terms of characters sampled and terminals included. The results obtained can be interpreted as a mere experimentation with the chosen methods. At this point we can present only tentative and preliminary interpretation of the genome evolution and origin of polyploid taxa. Despite of the limited taxonomic sampling there is a strong congruence with phylogenies obtained in previous molecular marker analyses using different datasets [39, 40] and broader sampling [6, 54-58, 62, 63]. In addition to the difficult interpretation of the observed morphological variation, genome relationships among the diploid and polyploid taxa are still a matter of debate. Despite of the great 


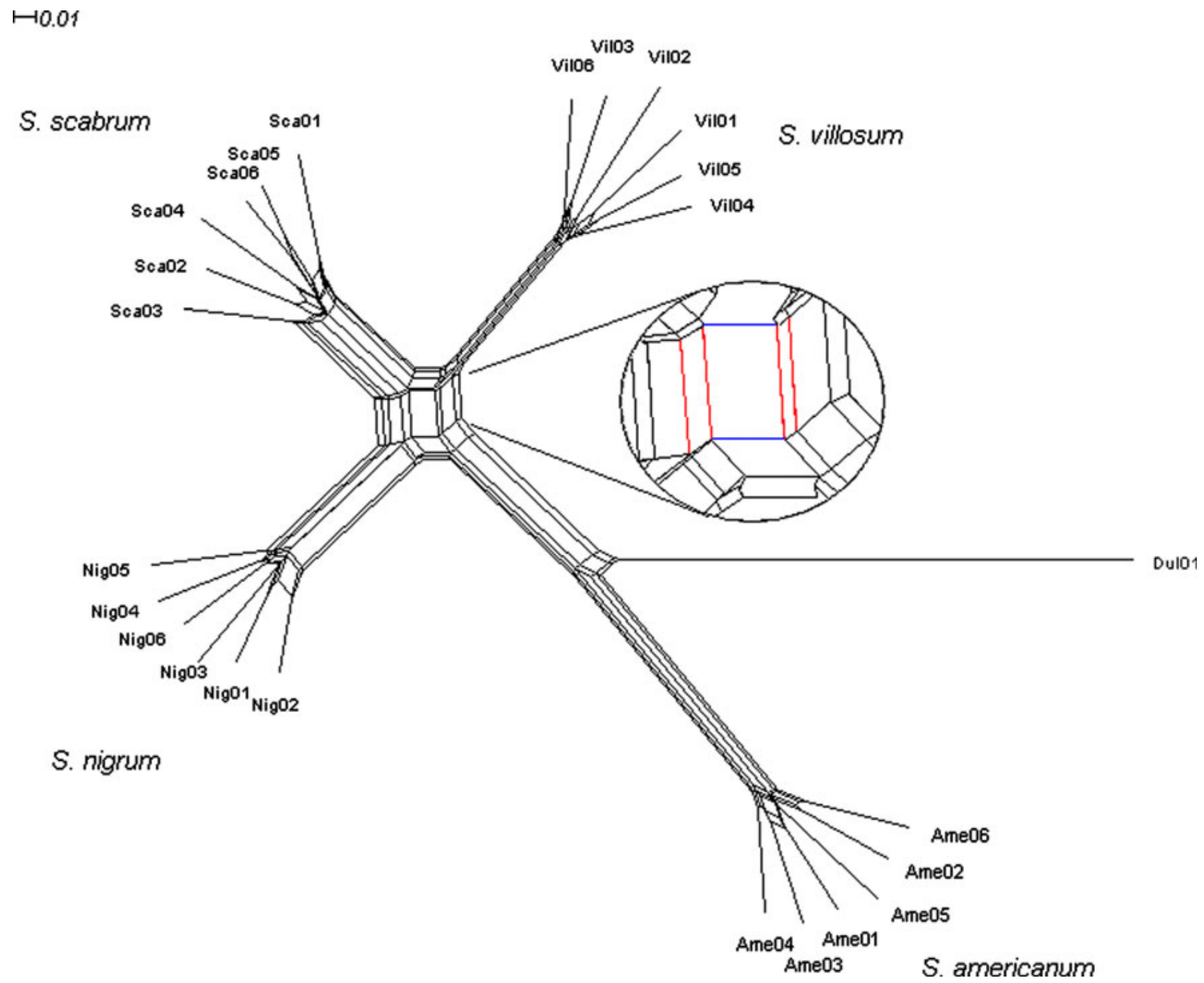

Fig. 2 NNet specific analysis of evolutionary history of S. nigrum with other terminals excluded, inferred from the combined ISSR and SCoT data based on uncorrected $p$-distances, with 0.95 threshold level. The inlet, a 'splits rose' illustrates the competing relationships

efforts to resynthetize polyploids using the combination of different crosses of species, e.g. [107, 109, 110], the exact origin and phylogeny of even the most widespread and common species like $S$. nigrum, have remained ambiguous. The first hybridization studies with early seed protein electrophoresis experiments [111] provided the preliminary hypothesis of the origin and the idea of complex reticulating events as reasonable scenarios of evolutionary history for some polyploids. It now seems clear that the complexity of this widespread and important group is based on polyploids.

On the origin of $S$. nigrum: taxonomic implications

The first studies on genomic relationships started with the identification of the possible progenitors of $S$. nigrum, which was referred as an autoallohexaploid [112] or autohexaploid $[107,113]$ and in other studies as an allohexaploid [25] species. The confusion around the origin of and supposed reticulate history of S. nigrum. Major splits highlighted with blue and red color indicate parallel edges structure in a 'box form' indicating incongruence in the collected splits (bipartitions)

S. nigrum could be attributed to its meiotic chromosomal behavior. The phenomenon that most species of the section show regular bivalent formation at meiosis or somatic chromosome doubling led early cytological workers to contradictory conclusions [24, 113-115]. Under a standard evolutionary model, the split graph reveals a reticulate evolutionary history of this species. In previous molecular studies based on different methods involving variable species a close relationship between $S$. scabrum, S. nigrum and S. villosum have been proposed [44, 58, 62], but contra Olet [40]. However, in a later parsimony analysis by Manoko [7] many of the species relationships were left as unresolved in the jackknife consensus tree. Although, it might be possible that the names are misapplied there, since what is referred by Manoko et al. [6] as $S$. americanum is probably $S$. ptycanthum from North America, and what is identified as $S$. nodiflorum is might be $S$. americanum.

In our simultaneous analysis $S$. villosum turned out to be a sister species of $S$. scabrum. The split graph constructed 


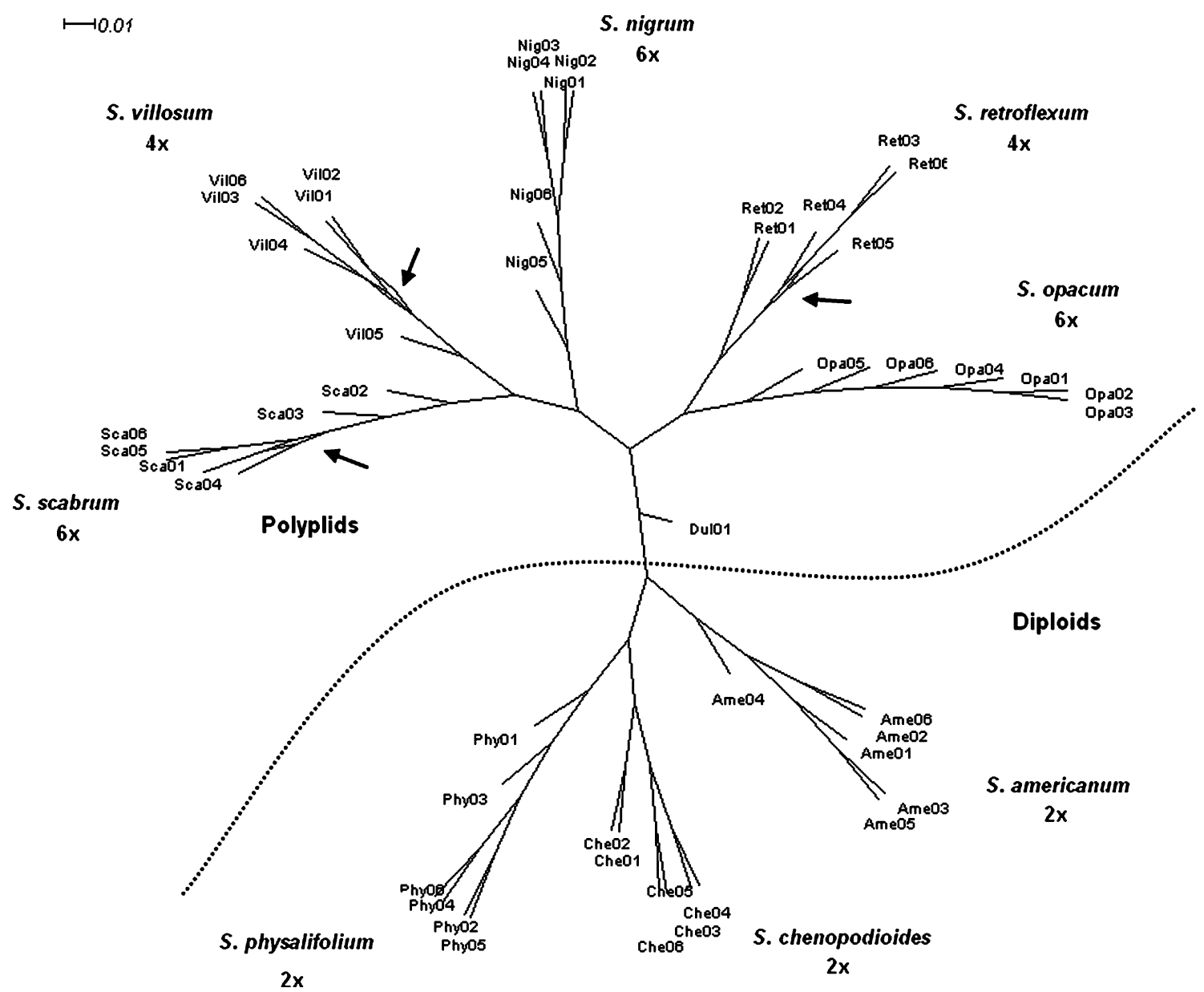

Fig. 3 SplitsTree supernetwork of the eight equally parsimonious trees (EPTs) inferred from the total evidence matrix (consensus data of morphology, trnL-F sequences and morphology). Black arrows indicate splits (bipartitions) supported by this analysis

from multi-locus binary data supports $S$. nigrum, $S$ scabrum and $S$. villosum as closely related. This might indicate that the tetraploid S. villosum contributed to both of the mentioned hexaploid taxa. The strong split (Fig. 1, highlighted in blue) combining the three taxa might indicate that they all share the same diploid ancestor. The terminals of these four species in exclusion of other taxa were represented in a separate analysis (Fig. 2) because they were assumed to share complex reticulate history. In both split graphs (Figs. 1 and 2) the tetraploid S. villosum was linked only with one diploid species $S$. americanum, suggesting its autotetraploid origin. These results confirm the fluorescent chromosome banding study of Sultana and Alam [116], where $S$. villosum was shown to be an ancient tetraploid of S. americanum s.l., which in the course of its evolution had established regular meiosis (bivalent formation). Rao [112] showed that from the two of the three sets of S. nigrum chromosomes are homologous with each other, and possibly originated from $S$. villosum. The remaining set differs from these two. As presented here S. nigrum possibly originated from diploid species S. americanum s.l. and tetraploid S. villosum through amphiploidy of sterile triploid progeny as previously presented $[27,107,108,117$ $120]$. Whether it can be coined as an autoallopolyploid depends on the degree of differentiation of the $S$. villosum genome as compared to the remaining set possibly originated from $S$. americanum s.l. If this is not the case, and only minute changes have been rearranged it could be regarded as a segmental allopolyploid. This needs to be verified by a precise molecular cytogenetic analysis. It is also evident that $S$. americanum s.l. provided its genome to S. scabrum too, as suggested by Ganaphati and Rao [121] based on the vigor of sterile hybrids derived from crossings. The crossing experiments carried out by Heiser et al. [122] also led to the same conclusions, alongside with other recent studies based on molecular markers [7, 39, 41, 44].

The separation of the other tetraploid taxa $S$. retroflexum with the hexaploid $S$. opacum in a well established group which is connected with parallel edges (Fig. 1 highlighted with green) to diploids $S$. chenopodioides and $S$. physalifolium is also interesting. The separation of diploids with one clear split confirms the conclusion by Manoko et al. 
[62], that $S$. americanum s.l. is not evolutionary related to $S$. physalifolium and S. chenopodioides. Moreover the latter species, or closely related species, possibly contributed their genome to $S$. retroflexum and $S$. opacum. Jacoby and Labuschagne [1] reported that crosses made between $S$. chenopodioides and $S$. retroflexum were much more successful than between $S$. americanum and S. retroflexum. In a previous study using AFLP Jacoby et al. [59] also confirmed close relationship between $S$. chenopodioides and $S$. retroflexum. Van der Walt et al. [123] using whole genome DArT analysis also reached the same conclusion. S. opacum occur in Australia and it was introduced to Tasmania in the 1800s and the early 1900s, but it was not recorded there since 1932 [124]. This species could represent an early dispersal event in the group possibly dating back to the separation of South America and Australia. After this it went through a polyploidization event involving other diploids related to $S$. chenopodioides or S. physalifolium.

\section{Can networks help?}

The NeighborNet algorithm found several parallel paths (edges), within the collection of splits, indicating the presence of phylogenetic incompatibilities. Evolutionary graphs based on split networks add extra topology-related parameters to phylogenetic analysis, allowing the constructed network to fit the data better than individual trees [70]. While network and parsimony analyses can be considered to have provided congruent results it should be kept on mind that the NeighborNet approach suffers from the same shortcomings as neighbor-joining: it is a distance based method, purely algorithmic producing circular collections of splits. However, Bryant and Moulton [69] claim that the mathematical algorithm collects classes of distance matrices which include treelike distances and matrices generated by a large range of evolutionary history. In other words, it creates splits (bipartitions) anytime there is a deviation from additivity in the distance matrix and the causes of these deviations could be attributed to several effects not just reticulation (i.e. hybrid speciation, polyploidization). It is possible that more exhaustive analyses, with explicitly defined optimality criteria (parsimony, maximum likelihood), might have given results that differ from those obtained here. Our sampling is also restricted: it does not include all geographical regions of diversity within and among the species.

However, another reasonable explanation to the obtained NNet topologies could be the rearrangement of the polyploid genomes. The distribution of all incompatible splits (exceeding the 0.95 threshold level) based on uncorrected $p$-distances are represented as splits (bipartitions), visualizing conflicting signals in the data sets, whether they arise from sampling error, or, are due to genuine recombination. It is well known that polyploidization can promote rapid essential rearrangements in the genome e.g. [125, 126] together with extensive and rapid genome restructuring [127], intergenomic recombination [125] and/or a rapid loss of DNA [128] accompanied with epigenetic remodeling [129]. As the majority of our data was produced by multi-locus ISSR and SCoT techniques generating random, or functional gene region related banding patterns spanning through the whole genome, it is obvious that these techniques are influenced by genomic rearrangements. With the ability to represent alternative phylogenetic histories in the analysis (recombination, hybridization) we have extracted phylogenetic signals not displayed by tree-based methods but we have also visualized those probably attributed to genomic rearrangements of polyploids. These intergenomic recombinations of the polyploid genomic DNA can result in significant changes in the patterns produced by PCR applying multi-locus markers. However, as the basic principles of the two techniques (ISSR, SCoT) differ from each other, and they generate patterns from different regions of the genome the results produced by these techniques were congruent.

While the NNet is possibly able to detect signals from hybrid speciation, it also has a high false negative rate. Accordingly, the separation of the diploid and polyploid species clearly visible in Fig. 1 might be attributed by rearrangement of polyploid genomes, as the Phi test of the filtered diploid taxa did not show any significant support for recombination $(P=0.5081)$. The collection of trees from the parsimony analysis of the joined ISSR and SCoT data had congruent topologies with relatively few reticulations and the supernetwork was almost tree-like (Fig. 3), strengthening the genomic rearrangement hypothesis. This suggests that, although recombination may have occurred among the terminals, there is still a common phylogenetic signal within the datasets. The construction of such consensus- or supernetworks makes sense in cases where relatively few hybridizations and reticulation events are expected. In this case where many of the analyzed terminals probably have complex evolutionary history, it is unrealistic to expect to be able to build a reticulate phylogeny [130]. Accordingly, application of such multi-locus markers like ISSRs and SCoTs could produce incorrect genetic distances depending on the degree of genome rearrangements. As a result, genetic distances between hypothetical parental diploids and their derived allopolyploids estimated by PCR-based multi-locus banding patterns will increase. As in this case polyploids like S. nigrum and possibly other members of section Solanum have undergone substantial genomic rearrangements in their genome. Therefore, other methods (e.g. sequence based approaches) should be used for the detection of 
polyploidy origin in the future studies. Phylogenetic analyses based on multiply sequences, combined with filtered supernetwork reconstruction have been used to detect incongruences and reticulations within larger datasets in different organisms up to class level [131]. Splits graphs and network based approaches have the potential to reveal reticulate history of black nightshades (sect. Solanum), but different methods should be chosen for further research, and the use of multi-locus markers should be avoided. An alternative to this would be the use of the complex nature of the rDNA locus (ITS, ETS) as suggested by Poczai and Hyvönen [132]. Accordingly, this region seems to be a warranted choice since it has been successfully utilized by Komarova et al. [126] together with NNet approaches to investigate the hybrid origin of Solanum sect. Petota.

\section{Conclusions}

Hybridization seems to be an important phenomenon in sect. Solanum and history of S. nigrum might be reticulate. Based on recent studies, e.g. [133], ancestors of Solanaceae and Solanum have gained one whole genome duplication (WGD) early in their evolutionary history, then the potato clade has gone through another [134]. S. nigrum represents a case where possibly ancient tetraploids and diploids formed a hexaploid species and these hybrids managed to exploit better their new habitat. In this case genetically differentiated diploids in a few combinations have created a series of genetically distinct polyploid populations. The gene flow between these new polyploids has not always been restricted, because different independent combinations have also arisen in the evolutionary history (e.g. S. opacum). The insufficient isolation that permitted further recombination between ancient polyploids and diploids have resulted in high level of genotypic and phenotypic polymorphism. This high level of novel genomic variability enabled species to succeed in their new environment (e.g. Africa, Asia or Australia). It is also interesting to note that both allo- and autopolyploidy, or the combination of these together with recurrent polyploidization, have also acted during the evolution and formation of $S$. nigrum and possibly in sect. Solanum too. It is possible that polyploids are formed over and over again subsequently from different parental genotypes and generate diverse array of species series. Hybridization among the polyploids has obviously also occurred and resulted in additional genetic variability. This feature of plants is not restricted to Solanum as it is well known that polyploids arose recurrently during flowering plant evolution [66].

In the future, intergenomic translocations-if presenthas to be identified in this group as previously proposed in allopolyploid species of Nicotiana of the same family
[127]. These studies involving chromosome painting and cytogenetic tools have potential to shed light on the complex processes that has acted during the evolutionary history of Solanum and help to elucidate the precise origin of polyploids. These kind of studies will be highly valuable for practical research programs (e.g. resistance genes and other important traits) aiming to utilize the genetic resources of this group. Despite of the complexity and possible multiple origins of the polyploids the group is still a rich source of unexploited new traits which should be utilized in the further improvement of the crop plants of Solanaceae. The difficult problem of completely unraveling the composite history of the section remains, although it is demonstrated that the application of recently developed phylogenetic network methods could provide the valuable first step towards the better understanding of its complex evolutionary history.

Acknowledgements We thank the staff of the Potato Research Center, University of Pannonia for their work; and several Botanical Gardens, collectors for the plant material. A special thank is due to the Staff of the Biotechnology Group, University of Pannonia for general assistance and facilities. This study was supported by the CIMO Research Fellowship Grant and by the MÖBCIMO Finnish Government's Scholarship provided for the first author. The authors also thank Dr. Jennifer Edmonds for comments regarding this study.

\section{References}

1. Jacoby A, Labuschagne MT (2006) Hybridization studies of five species of the Solanum nigrum complex found in South Africa and two cocktail tomato cultivars. Euphytica 149:303-307

2. Edmonds JM, Chweya JA (1997) Black nightshades. Solanum nigrum L. and related species. Promoting the conservation and use of underutilized and neglected crops, vol 15. International Plant Genetic Resources Institute, Rome, Italy

3. Lehmann C, Biela C, Töpfl S, Jansen G, Vögel R (2007) Solanum scabrum - a potential source of a coloring plant extract. Euphytica 158:189-199

4. Mwai GN, Onyango JC, Abukusta-Onyango O (2007) Taxon identification and characterization of African nightshades (Solanum L. Section Solanum). Afr J Food Agric Nutr Dev 7(4):1-13

5. Schippers RR (2000) African indigenous vegetables. An overview of the cultivated species. Natural Resources Institute/ACPEU Technical Centre of Agriculture and Rural Cooperation, Catham, UK, pp 147-176

6. Manoko MLK, van der Weerden GM (2004) Solanum villosum. In: Grubben GJH, Denton OA (eds) Plant resources of Tropical Africa 2 vegetables. PROTA Foundation Wageningen/CTA Wageningen, Backuys Publishers, Leiden, The Netherlands, pp 503-507

7. Manoko MLK (2007) A systematic study of African Solanum L. section Solanum (Solanaceae). PhD thesis, Radboud Univesity Nijmegen, The Netherlands

8. Flier WG, van der Bosch GMB, Turkensteen LJ (2003) Epidemiological importance of Solanum sisymbriifolium, $S$ nigrum and $S$. dulcamara as alternative hosts for Phytophthora infestans. Plant Pathol 52:595-603 
9. Lebecka R (2008) Host-pathogen interaction between Phytophthora infestans and Solanum nigrum, S. villosum, and S. scabrum. Eur J Plant Pathol 120:233-240

10. Kamoun S, Huitema E, Vleeshouwers VGAA (1999) Resitance to Oomycetes: a general role of the hypersensitive response? Trends Plant Sci 4:196-200

11. Campos MA, Ribeiro SG, Rigden DJ, Monte DC, Grossi de Sa MF (2002) Putative pathogenesis-related genes within Solanum nigrum L. var. americanum genome: isolation of two gnes soding for PR5-like proteins, phylogenetic and sequence analysis. Physiol Mol Plant Pathol 61(4):205-216

12. Colon LT, Eijlander R, Budding DJ, Pieters MMJ, Hoogendoorn J, Van-Ijzendoorn MT (1993) Resistance to potato late blight (Phytophthora infestans (Mont.) de Bary) in Solanum nigrum, $S$. villosum and their sexual hybrids with $S$. tuberosum and S. demissum. Euphytica 66:55-64

13. Eijlander R, Stiekema WJ (1994) Biological containment of potato (Solanum tuberosum): outcrossing to the related wild species black nightshade (Solanum nigrum) and bittersweet (Solanum dulcamara). Sex Plant Reprod 7:29-40

14. Horsman K, Bergervoet JEM, Jacobsen E (1997) Somatic hybridization between Solanum tuberosum and species of the $S$ nigrum complex: selection of vigorously growing and flowering plants. Euphytica 96:345-352

15. Zimnoch-Guzowska E, Lebecka R, Kryszczuk A, Maciejewska U, Szczerbakowa A, Wielgat B (2003) Resistance to Phytophthora infestans in somatic hybrids of Solanum nigrum L and diploid potato. Theor Appl Genet 107:43-48

16. Lebecka R (2009) Inheritance of resistance in Solanum nigrum to Phytophthora infestans. Eur J Plant Pathol 124:345-348

17. Flor HH (1942) Inheritance of pathogenicity in Melamspora lini. Phytopathology 32:653-669

18. Flor HH (1971) Current status of the gene-for-gene concept. Annu Rev Phytopathol 9:275-296

19. Child A, Lester RN (2001) Synopsis of the genus Solanum L. and its infrageneric taxa. In: van den Berg RG, Barendse GWM, van der Weerden GM, Mariani C (eds) Solanaceae V: advances in taxonomy and utilization. Nijmegen University Press, Nijmegen, pp 39-52

20. Edmonds JM (1972) A synopsis of the taxonomy of Solanum L section Solanum (Maurella) in South America. Kew Bull 27:95-114

21. Edmonds JM (1986) Biosystematics of Solanum sarrachoides Sendtn and S. physalifolium Rubsy (S. nitidibaccatum Bitter). Bot J Linn Soc 92:1-38

22. Stabbins GL Jr, Paddock EF (1949) The Solanum nigrum complex in Pacific North America. Madroño 10:70-81

23. D'Arcy WG (1974) Solanum and its close relatives in Florida. Ann Miss Bot Gard 61(3):819-867

24. Henderson RJF (1974) Solanum nigrum L (Solanaceae) and related species in Australia. Contrib Queensl Herb 16:1-78

25. Edmonds JM (1979) Biosystematics of Solanum L. section Solanum (Maurella). In: Hawkes JG, Lester RN, Skelding AD (eds) The biology and taxonomy of the Solanaceae. Academic Press, London, pp 529-548

26. Lester RN, Daunay M-C (2003) Diversity of African vegetable Solanum and its implications for a better understanding of plant domestication. In: Küpfer H, Ochsmann J (eds) Rudolf mansfeld and plant genetic resources. Proceedings of a symposium dedicated for the 100th birthday of Rudolf Mansfeld. Schriften zu genetischen Ressourcen, Band 22, pp 137-152

27. Venkateswarlu J, Rao MK (1972) Breeding systems, crossablilty relationships and isolating mechanisms in the Solanum nigrum complex. Cytologia 37:317-326

28. Leslie AC (1978) The occurrence of Solanum nigrum $\mathrm{L} \times S$ sarrachoides Sendtn in Britain. Watsonia 12(1):29-32
29. Edmonds JM (1981) The artificial synthesis of Solanum $\times$ procurrens Leslie ( $S$ nigrum L. $\times S$. sarrachoides Sendtn). Watsonia 13:203-233

30. Linnaeus C (1753) Species plantarum, vol 2. Stockholm

31. Defelice MS et al (2003) The black nightshades, Solanum nigrum L-poison, poultice, and pie. Weed Technol 17:421-427

32. Ogg AG Jr, Rogers BS, Schilling EE (1981) Characterization of black nightshade (Solanum nigrum) and related species in the United States. Weed Sci 29:27-32

33. Schilling EE (1981) Systematics of Solanum sect Solanum (Solanaceae) in North America. Syst Bot 6:172-185

34. Edmonds JM (2005) Solanum L. section Solanum. In: Pope GV, Martin ES (eds) Flora Zambesiaca, vol 8(4). Royal Botanic Gardens, Kew, UK, pp 81-86

35. Edmonds JM (2006) Solanum L. section Solanum. In: Thulin M (ed) Flora Somalia, vol 3. Royal Botanic Gardens, Kew, UK, pp 207-208

36. Planetary Biodiversity Inventory Solanum Project. http://www. nhm.ac.uk/solanaceaesource/

37. Knapp S, Bohs L, Nee M, Spooner DM (2004) Solanaceae: a model for linking genomics with biodiversity. Comp Funct Genom 5:285-291

38. Dehmer KJ (2001) Conclusions on the taxonomy of the Solanum nigrum complex by molecular analysis of IPK germplasm accessions. In: van den Berg RG, Barendse GWM, van der Weerden GM, Mariani C (eds) Solanaceae V: advances in taxonomy and utilization. Nijmegen University Press, The Netherlands, pp 85-96

39. Jacoby A (2003) Genetic variability in the Solanum nigrum complex and related species in South Africa. PhD thesis, University of the Free State Bloemfontein, South Africa

40. Olet EA (2004) Taxonomy of Solanum L. section Solanum in Uganda. PhD thesis, Agricultural University of Norway

41. Poczai P (2007) Phylogenetic analysis of infrageneric groups in the genus Solanum. MSc thesis, University of Pannonia, Hungary

42. Bohs L (2005) Major clades in Solanum based on $n d h \mathrm{~F}$ sequences. In: Keating RC, Hollowell VC, Croat TB (eds) A festschrift for William G. D'Arcy: the legacy of a taxonomist. Monographs in Systematic Botany from the Missouri Botanical Garden, vol 104. Missouri Botanical Garden Press, St. Louis, pp 27-49

43. Weese TL, Bohs L (2007) A three-gene phylogeny of the genus Solanum (Solanaceae). Syst Bot 32(2):445-463

44. Poczai P, Taller J, Szabó I (2008) Analysis of phylogenetic relationships in the genus Solanum (Solanaceae) as revealed by RAPD markers. Plant Syst Evol 275:59-67

45. Danert S (1970) Infragenerische Taxa der Gattung Solanum L. Kulturpflanze 18:253-297

46. D'Arcy WG (1972) Solanaceae studies II: typification of subdivisions of Solanum. Ann Miss Bot Gard 59:262-278

47. D'Arcy WG (1991) The Solanaceae since 1976, with a review of its biogeography. In: Hawkes JG, Lester RN, Nee M, Estrada N (eds) Solanaceae III: taxonomy, chemistry, evolution. Royal Botanic Gardens, Kew, UK, pp 75-137

48. Bohs L, Olmstead RG (1997) Phylogenetic relationships in Solanum (Solanaceae) based on $n d h \mathrm{~F}$ sequences. Syst Bot 22:517

49. Bohs L, Olmstead RG (1999) Solanum phylogeny inferred from chloroplast DNA sequence data. In: Nee M, Symon DE, Lester RN, Jessop JP (eds) Solanaceae IV: advances in biology and utilization. Royal Botanic Gardens, Kew, UK, pp 97-110

50. Olmstead RG, Palmer JD (1997) Implications for the phylogeny, classification, and biogeography of Solanum from cpDNA restriction site variation. Syst Bot 22:19-29 
51. Hunziker AT (2001) The genera of Solanaceae. ARG Gantner Verlag, Ruggel, Lichtenstein

52. Pamidimarri DVNS, Mastan SG, Rahman H, Reddy MP (2009) Molecular characterization and genetic diversity analysis of Jatropha curcas L. in India using RAPD and AFLP analysis. Mol Biol Rep. doi:10.1007/s11033-009-9712-2

53. Kumar RS, Parthiban KT, Rao MG (2009) Molecular characterization of Jatropha genetic resources through inter-simple sequence repeat (ISSR) markers. Mol Biol Rep 36:1951-1956

54. Stracke S, Njoroge G, Hammer K (1996) Genetic diversity in the collection of Solanum nigrum L the Gatersleben genebank. In: Begmann F, Ehling C, Falge R (eds) Vergleichende aspekte der nutzung und erhaltung pflanzen- und tiergenetischer ressourcen (Schriften zu genetischen ressourcen, 5). IGR/ZADI, Bonn, pp 320-324

55. Poczai P, Mátyás K, Taller J, Szabó I (2010) Study on the origin of the rarely cultivated edible Solanum species: morphological and molecular data. Biol Plant 54(3):543-546

56. Dehmer KJ, Stracke S (1999) Molecular analyses of genebank accessions of the Solanum nigrum complex. In: Andrews S, Leslie AC, Alexander C (eds) Third international symposium on the taxonomy of cultivated plants. Royal Botanic Gardens, Kew, UK, pp 343-345

57. Dehmer KJ (2003) Molecular genome analyses as tool for efficient ex situ conservation and utilization of plant genetic resources. In: Forsline PL, Fidegheli C, Richards K, Meerow A, Nienhus J, Williams D, Thörn E, Tombolato AFC, Knüpffer H, Stoner A (eds) Plant genetic resources: the fabric of horticulture's future. Proceedings of the XXVI interantional horticultural congress, 11-17 August 2002, Toronto, Canada, pp 151160

58. Dehmer KJ, Hammer K (2004) Taxonomic status and geographic provenance of germplasm accessions in the Solanum nigrum L complex: AFLP data. Genet Res Crop Evol 51:551558

59. Jacoby A, Labuschagne MT, Viljoen CD (2003) Genetic relationships between Southern African Solanum retroflexum Dun and other related species measured by morphological and DNA markers. Euphytica 132:109-113

60. Olet EA, Huen M, Lye KA (2005) African crop or poisonous nightshade; the enigma of poisonous or edible black nightshades solved. Afr J Ecol 43:158-161

61. Olet EA, Heun M, Lye KA (2006) A new subspecies of Solanum scabrum Miller found in Uganda. Novon 16:508-511

62. Manoko MLK, van den Berg RG, Feron RMC, van der Weerden GM, Mariani C (2007) AFLP markers support separation of Solanum nodiflorum from Solanum americanum senu stricto (Solanaceae). Plant Syst Evol 267:1-11

63. Manoko MLK, van den Berg RG, Feron RMC, van der Weerden GM, Mariani C (2008) Genetic diversity of the African hexaploid species of Solanum scabrum Mill. and Solanum nigrum L. (Solanaceae). Genetic Res Crop Evol 55(3):409-418

64. Poczai P, Taller J, Szabó I (2009) Molecular genetic study on a historical Solanum (Solanaceae) herbarium specimen collected by Paulus Kitaibel in the 18th century. Acta Bot Hung 51(34):337-346

65. Makarenkov V, Legendre P, Desdevises Y (2003) Modeling phylogenetic relationships using reticulated networks. Zool Scr 33(1):89-96

66. Soltis PS (2005) Ancient and recent polyploidy in the angiosperms. New Phytol 166:5-8

67. Linder CR, Rieseberg LH (2004) Reconstructing patterns of reticulate evolution in plants. Am J Bot 91(10):1700-1708

68. Nakhleh L (2010) Evolutionary phylogenetic networks: models and issues. In: Health L, Ramakrishnan N (eds) The problem solving handbook for computational biology and bioinformatics. Springer, New York, pp 1-34

69. Bryant D, Moulton V (2004) NeighborNet: an agglomerative method for the construction of phylogenetic networks. Mol Biol Evol 21(2):255-265

70. Huson DH, Bryant D (2006) Application of phylogenetic networks in evolutionary studies. Mol Biol Evol 23:254-267

71. Collard BCY, Mackill DJ (2009) Start codon targeted (SCoT) polymorphism: a simple, novel DNA marker technique for generating gene-targeted markers in plants. Plant Mol Biol Rep 27:86-93

72. Jacobs MMJ, van den Berg RG, Vleeshouwers VGAA, Visser M, Mank R, Sengers M, Hoeskatra R, Vosman B (2008) AFLP analysis reveals a lack of phylogenetic structure within Solanum section Petota. BMC Evol Biol 8:145

73. Kingston SE, Adams LD, Rosel PE (2009) Testing mitochondrial sequences and anonymous nuclear markers for phylogeny reconstruction in a rapidly radiating group: molecular systematics of Delphininae (Cetacea:Odontoceti:Delphinidae). BMC Evol Biol 9:245

74. Rubio-Moraga A, Castillo-López R, Gómez-Gómez L, Ahrazem O (2009) Saffron is a monomorphic species as revealed by RAPD, ISSR and microsatellite analyses. BMC Res Notes 2:189

75. Croll D, Sanders IR (2009) Recombination in Glomus intraradices, a supposed ancient asexual arbuscular mycorrhizal fungus. BMC Evol Biol 9:13

76. Davierwala AP, Ramakrishna W, Chowdari V, Ranjekar PK, Gupta VS (2001) Potential of (GATA) microsatellites from rice for inter- and intra-specific variability studies. BMC Evol Biol $1: 7$

77. Awasthi AK, Nagaraja GM, Naik GV, Kanginakdudru S, Thangavelu K, Nagaraju J (2004) Genetic diversity and relationships in mulberry (genus Morus) as revealed by RAPD and ISSR marker assays. BMC Genetics 5:16

78. Sica M, Gamba G, Montieri S, Gaudio L, Aceto S (2005) ISSR markers show differentiation among Italian populations of Asparagus acutifolius L. BMC Genetics 6:17

79. Jones CJ, Edwards KJ, Castaglione S, Winfield MO, Sala F, van de Wiel C, Bredemejer G, Vosman B, Matthes M, Daly A, Brettschneider R, Bettini P, Buiatti M, Maestri E, Malcevschi A, Marmiroli N, Aert E, Volckaert G, Lincero R, Rueda J, Vazquez A, Karp A (1997) Reproducibility testing of RAPD, AFLP and SSR markers in plants by a network of European laboratories. Mol Breed 3:381-390

80. Meudt HM, Clarke AC (2007) Almost forgotten or latest practice? AFLP applications, analyses and advances. Trends Plant Sci 12:106-117

81. Koopman WJM (2005) Phylogenetic signal in AFLP data sets. Syst Biol 54:197-217

82. Kardolus JP, van Eck HJ, van den Berg RG (1998) The potential of AFLPs in biosystematics: a first application in Solanum taxonomy. Plant Syst Evol 210:87-103

83. Van den Berg RG, Bryan G, del Rio A, Spooner DM (2002) Reduction of species in the wild potato Solanum section Petota series Longipedicellata: AFLP, RAPD and chloroplast SSR data. Theor Appl Genet 105:1109-1114

84. Lara-Cabrera SI, Spooner DM (2004) Taxonomy of North and Central American diploid wild potato (Solanum sect Petota) species: AFLP data. Plant Syst Evol 248:129-142

85. McGregor CE, van Treuren E, Hoekstra R, van Hintum ThJL (2002) Analysis of the wild potato germplasm of the series Acaulia with AFLPs: implications for ex situ conservation. Theor Appl Genet 104:146-156

86. Spooner DM, McLean K, Ramsay G, Waugh R, Bryan GJ (2005) A single domestication for potato based on multilocus 
amplified fragment length polymorphism genotyping. PNAS 102:14694-14699

87. Taberlet P, Gielly L, Pautou G, Bouvet J (1991) Universal primers for amplification of three non-coding regions of chloroplast DNA. Plant Mol Biol 17(5):1105-1109

88. Kingston SE, Rosel PE (2004) Genetic differentiation among recently diverged Delphinid taxa determined using AFLP markers. J Hered 95:1-10

89. Botstein D, White RL, Skolnick M, Davis RW (1980) Construction of a genetic linkage map in man using restriction fragment length polymorphisms. Am J Hum Genet 32:314-331

90. Liu BH (1998) Statistical genomics: linkage, mapping and QTL analysis. CRC Press, New Yrok, pp 158-159

91. PICcalc an online program for calculating Polymorphic Information Content (PIC). http://www.georgikon.hu/pic/english

92. Henry RJ (1997) Practical applications of plant molecular biology. Chapman \& Hall, London, pp 59-98

93. De Riek J, Calsyn E, Everaert I, Van Bockstaele E, De Loose M (2001) AFLP based alternatives for the assessment of distinctness, uniformity and stability of sugar beet varieties. Theor Appl Genet 103:1254-1265

94. Bolaric S, Barth S, Melchinger AE, Posselt UK (2005) Genetic diversity in European perennial rygrass cultivars investigated with RAPD markers. Plant Breed 124:161-166

95. SPLITSTREE v.4.6. http://www.splitstree.org

96. Bruen TC, Philippe H, Bryant D (2006) A simple and robust statistical test for detecting the presence of recombination. Genetics 172:2665-2681

97. Jeanmougin F, Thompson JD, Gouy M, Higgins DG, Gibson TJ (1998) Multiple sequence alignment with Clustal X. Trends Biochem Sci 23:403-405

98. Goloboff PA (1994) NONA: a tree searching program. Program and documentation. www.cladistics.com/aboutNona.htm

99. Nixon KC (2002) Winclada. Version 1.00.08. www.cladistics. com/aboutWinc.htm. the author, Ithaca, NY

100. Goloboff PA, Farris JS, Nixon KC (2008) TNT, a free program for phylogenetic analysis. Cladistics 24:774-786

101. Saitou N, Nei M (1987) The neighbor-joining method: a new method for reconstructing phylogenetic trees. Mol Biol Evol 4(4):406-425

102. Kilian B, Özkan H, Deusch O, Effgen S, Brandolini A, Kohl J, Martin W, Salamini F (2007) Independent wheat B and G genome origins in outcrossing Aegilops progenitor haplotypes. Mol Biol Evol 24(1):217-227

103. Esser C, Ahmadinejad N, Wiegand C, Rotte C, Sebastiani F, Gelius-Dietrich G, Henze K, Kretschmann E, Richly E, Leister D, Bryant D, Steel MA, Lockhart P, Penny D, Martin W (2004) A genome phylogeny for mitochondria among $\alpha$-proteobactera and predominantly eubacterial ancestry of yeast nuclear genes. Mol Biol Evol 21(9):1643-1660

104. Holland BR, Benthin S, Lockhart PJ, Moulton V, Huber KT (2008) Using supernetworks to distinguish hybridization from lineage-sorting. BMC Evol Biol 8:202

105. Meudt HM, Lockhart PJ, Bryant D (2009) Species delimitation and phylogeny of New Zealand plant species radiation. BMC Evol Biol 9:111

106. Willerslev E, Gilbert MTP, Binladen J, Ho SYW, Campos PF, Ratan A, Tomsho LP, da Fonseca RR, Sher A, Kuzentsova V, Nowak-Kemp M, Roth TL, Miller W, Schuster SC (2009) Analysis of complete mitochondrial genomes from extinct and extant rhinoceroses reveals lack of phylogenetic resolution. BMC Evol Biol 9:95

107. Tandon SL, Rao GR (1966) Genome analysis in Solanum nigrum L. J Cytol Genet 1:41-45

108. Soria J, Heiser CB Jr (1959) The garden huckleberry and the sunberry. Baileya 7:33-35
109. Rao GR, Khan R, Khan AH (1977) Cytomorphology and nature of sterility barriers of interspecific hybrids of some species of Solanum nigrum complex. Indian J Genet Plant Breed 37(7):54-61

110. Bhiravamurty PV, Rethy P (1984) Origin and evolution of tetraploid forms within the Solanum nigrum L complex. Proc Indian Acad Sci (Plant Sci) 93(5):553-560

111. Edmonds JM, Glidewell SM (1977) Acrylamide gel electrophoresis of seed proteins from some Solanum (section Solanum) species. Plant Syst Evol 127:277-291

112. Rao MK (1971) Cytology of a pentaploid hybrid and genome analysis in Solanum nigrum L. Genetica 42:157-164

113. Chennaveeraiah MS, Patil SR (1968) Some studies in the Solanum nigrum L complex. Genetica Iberica 20:23-26

114. Rao GR, Tandon SL (1969) Relationships between tetraploid Solanum nigrum and Solanum luteum. Sci Cult 35:688-689

115. Sharma AK, Bal AK (1961) Cytological studies in several species of non-tuberiferous Solanum with special reference to polyploid types of $S$. nigrum L. In: Proceedings of the 48th Indian science congress Pt. III, pp 295-296

116. Sultana SS, Alam SS (2007) Fluorescent chromosome banding of Solanum nigrum L and Solanum villosum L. from Bangladesh. Cytologia 72:213-219

117. Tandon SL, Rao GR (1964) Cytogenetical investigations in relation to mechanism of evolution in hexaploid Solanum nigrum L. Nature 201:1348-1349

118. Tandon SL, Rao GR (1974) Solanum nigrum L. In: Hutchinson SJB (ed) Evolutionary studies in world crops. Cambridge University Press, UK, pp 109-117

119. Venkateswarlu J, Rao MK (1969) Chromosome numerical mosaicism in some hybrids of the Solanum nigrum complex. Genetica 40:400-406

120. Venkateswarlu J, Rao MK (1971) Inheritance of fruit colour in the Solanum nigrum complex. Proc Indian Acad Sci B 74(3):137-141

121. Ganapathi A, Rao GR (1987) Cytology of hybrids between Solanum nigrum L and Solanum furcatum Dun. Proc Indian Acad Sci (Plant Sci) 97(5):371-375

122. Heiser CB, Soria J, Burton DL (1965) A numerical taxonomic study of Solanum species and hybrids. Am Nat 99:471-488

123. Van der Walt E, Van Schalkwyk A, Berger DK (2008) Genetic relationships between South African Solanum retroflexum and other related species using partial $18 \mathrm{~S}$ sequencing. S Afr J Bot 74(2):391

124. Kirkpatrick JB (1991) Tasmanian native bush: a management handbook. Tasmanian Environmental Centre, Hobart, Tasmania

125. Song K, Lu P, Tang K, Osborn TC (1995) Rapid genome change in systhetic polyploids of Brassica and its implications fro polyploid evolution. PNAS 92:7719-7723

126. Komarova NY, Grimm GW, Hemleben V, Volkov RA (2008) Molecular evolution of $35 \mathrm{~S}$ rDNA and taxonomic status of Lycopersicon within Solanum sect. Petota. Plant Syst Evol 276:59-71

127. Leitch IJ, Bennett MD (1997) Polyploidy in angiosperms. Trends Plant Sci 2:470-476

128. Özkan H, Levy AA, Feldman M (2001) Allopolyploidy-induced rapid genome evolution in the wheat (Aegilops-Triticum) group. Plant Cell 13:1735-1747

129. Osborn TC, Pires JC, Birchler JA, Auger DL, Chen ZJ, Lee H-S, Comai L, Madlung A, Doerge RW, Colot V, Martienssen RA (2003) Understanding mechanisms of novel gene expression in polyploids. Trends Genet 19(3):141-147

130. McBreen K, Lockhart PJ (2006) Reconstructing reticulate evolutionary histories of plants. Trends Plant Sci 11(8):398-404

131. Bell NE, Hyvönen J (2010) Phylogeny of the moss class Polytrichopsida (Bryophyta): generic-level structure and incongruent gene trees. Mol Phylogenet Evol 55:381-398 
132. Poczai P, Hyvönen J (2010) Nuclear ribosomal spacer regions in plant phylogenetics: problems and prospects. Mol Biol Rep 37:1897-1912

133. Schlueter JA, Dixon P, Granger C, Grant D, Clark L, Doyle JJ, Shoemaker RC (2004) Mining EST database to resolve evolutionary events in major crop species. Genome 47:868-876
134. Gebhardt C, Walkemeier B, Heselewski H, Barakat A, Delseny M, Stüber K (2003) Comparative mapping between potato (Solanum tubereosum) and Arabidopsis thaliana reveal structurally conserved domain and ancient duplications in the potato genome. Plant J 34:529-541 